\title{
The Development of Children with Disabilities by Means of Folk Plays
}

\author{
Gulfiya G. Parfilova ${ }^{1}$, Lilia S. Karimova ${ }^{1} \&$ Ramilya S. Kasimova ${ }^{1}$ \\ ${ }^{1}$ Kazan (Volga region) Federal University, Kazan, Russia \\ Correspondence: Gulfiya G. Parfilova, Kazan (Volga region) Federal University, Kremlyovskaya Street 18, \\ Kazan, 420008, Russia.
}

Received: December 29, 2014

Accepted: January 22, 2015 Online Published: February 11, 2015

doi:10.5539/res.v7n4p186

URL: http://dx.doi.org/10.5539/res.v7n4p186

\begin{abstract}
Every child with disabilities is unique both according to the state and the rate of development, therefore early correctional help is a means aimed to form those skills and abilities which the child is ready to perceive at the time; the help should be individualized as much as possible. Thus it is necessary to provide maximum opportunities for the child's development. Purposeful, laborious and patient work is required. Teachers should have a clear idea of how and what to teach the child, how to treat the child's behavior and difficulties during lessons, how to consider the child's abilities, to smooth the peculiarities of the child's state caused by disease. The article deals with the relevance of the problem, using play therapy with children with disabilities in psychological, educational, social and philosophical literature, the study of the problem in Russia, research methodology and experimental study on the issue. The results of pedagogical experiment allow to come to the conclusion about the effectiveness of the developed program which consist of different folk plays.
\end{abstract}

Keywords: children with disabilities, play therapy, folk plays

\section{Introduction}

\subsection{Actualization of the Problem}

A new system of values characteristic for the society and state at present and transition of special education system to an advanced level of its development have resulted in the necessity to reconsider the balance of the child's educational achievements and achievements in the field of social competence, the role and place of personal and social development of the child with disabilities

A considerable part of children with special needs is not ready to integrate into social-economic life when they become adult despite all the efforts undertaken by the society to train and bring them up. At the same time, results of researches and experience testify to the fact that any person having some development problems may become an active personality, may maturate spiritually, may secure themselves financially and be of great help for the society in case that appropriate conditions are created.

\subsection{Explore Importance of the Problem}

Every child with disabilities is unique both according to the state and the rate of development, therefore early correctional help is a means aimed to form those skills and abilities which the child is ready to perceive at the time; the help should be individualized as much as possible. Thus it is necessary to provide maximum opportunities for the child's development. Purposeful, laborious and patient work is required. Teachers should have a clear idea of how and what to teach the child, how to treat the child's behavior and difficulties during lessons, how to consider the child's abilities, to smooth the peculiarities of the child's state caused by disease, etc. (Akatov, 2003).

It is known that among many means of psycho-pedagogical support of children with disabilities the special place is taken by different forms and methods of a play therapy where a play is the most favorite type of their activity and communication. Play therapy is considered as the means of dynamic correction of disbalanced emotional-volitional, communicative and musculoskeletal spheres of preschool and primary school children. The expediency of play therapy in the organization of long-term rehabilitation to improve the health of children with similar medico-psychological indications in the specified spheres is caused, firstly, by the fact that a play is the most mastered and organic kind of activity and communication; secondly, there is presented the unity of 
psychological nature of a play and communication here; thirdly, the child can freely express themselves in a play, release from tension and frustration of everyday life. Finally, the play therapy represents unique experience for child's social and mental development, it opens opportunity to enter significant personal communication with the adult — a psychologist, a teacher, a parent, a guardian (Vygotsky, 2006).

\subsection{The concept of "Children with Disabilities"}

The concept "children with disabilities" covers the category of persons whose life activity is limited or there is lack of ability to perform any activity in the way or within the frames that are considered standard for the person of this age. This concept is characterized by excessiveness or insufficiency in comparison with conventional behavior or activity, may be temporary or constant, progressing and regressive (Sokolova, 2005).

In the course of interaction with the child with disabilities there arise many problems connected with the impact of a great number of external and internal factors on the developing personality. In order to operate this process effectively, it is necessary to know its specifics, positive and negative sides, to forecast the results of influence and to introduce amendments at the appropriate time.

\subsection{Status of a Problem}

Many teachers and psychologists considered the issue of folk plays application in children's education. The pedagogical potential of folk plays in the formation of preschool children's personality was specified by I. G. Pestalozzi, F. Froebel, P. F. Lesgaft, L. N. Tolstoy, N. K. Krupskaya, V. A. Sukhomlinsky. Famous psychologists L. S. Vygotsky, A. N. Leontyev, D. B. El' konin and other scientists have contributed to the development of the theory and practice of play. They emphasize the role and the importance of a play in child's development, formation of their personality.

In addition to the general theory of play activity, many researchers analyzed folk plays and their functions in teaching-educational process; they defined pedagogical techniques aimed to manage different types of folk plays for children's moral, speech, esthetic and physical development (Anikeev, 2011).

The experience of national pedagogics and modern achievements of psychological and pedagogical sciences give grounds to define prospects for the solution of issues concerning the upbringing, training and development of children with disabilities by means of folk plays.

The relevance of the problem is determined by the objective contradiction between the necessity of a new, creative approach to the organization and content of work with children having health problems with national and universal values taken into account and real-life practice of rendering correctional, pedagogical help to them, an insufficient study of the issue concerning the correctional orientation of folk plays.

The objective of our research is the study of folk plays correctional opportunities for children with disabilities.

\subsection{Hypothesis of the Study}

It is known that among many means of psycho-pedagogical support of children with disabilities the special place is taken by different forms and methods of a play therapy where a play is the most favorite type of their activity and communication. Play therapy is considered as the means of dynamic correction of disbalanced emotional-volitional, communicative and musculoskeletal spheres of preschool and primary school children. The expediency of play therapy in the organization of long-term rehabilitation to improve the health of children with similar medico-psychological indications in the specified spheres is caused, firstly, by the fact that a play is the most mastered and organic kind of activity and communication; secondly, there is presented the unity of psychological nature of a play and communication here; thirdly, the child can freely express themselves in a play, release from tension and frustration of everyday life. Finally, the play therapy represents unique experience for child's social and mental development, it opens opportunity to enter significant personal communication with the adult — a psychologist, a teacher, a parent, a guardian (Vygotsky, 2006).

This enabled to formulate hypotheses of the study: children's moral, speech, esthetic and physical development level would be higher if:

- To expand children's knowledge about national traditions; folk plays;

- To develop the interest in folk active plays;

- To include of folk developing plays in teaching-educational process. 


\section{Materials and Methods}

\subsection{The Tasks of the Research}

The study addressed the following objectives: 1) To analyze the psychological and pedagogical literature for the study of "children with disabilities" and "folk plays influences" notions; 2) To learn the assessment of interest development in folk active plays; 3 ) To describe the training as means of students' readiness for parenting formation; 4) To elaborated a program that includes folk active plays and folk plays-riddles, national games aimed to develop fine motor skills.

\subsection{Theoretical and Empirical Methods}

In compliance with the goal, the following methods have been selected:

- theoretical - analysis of the pedagogical and psychological literature; study and generalization of innovative pedagogical experience, analysis, synthesis;

- empirical-participant observation, ascertaining and forming pedagogical experiment, questionnaires, tests, interviews, conversations.

\subsection{Base of the Study}

Students and teachers from Institute of Psychology and Education, Kazan federal university have elaborated a program "The father Nahum give mind" and pedagogical experiment was held at school No. 111, Kazan city from December 2013 to March 2014. The study involved primary school children aged 7 to 10 years old.

\subsection{Stages of the Study}

The study was conducted in three phases:

In the first stage the experimental platform at school No. 111 Kazan city.

At the second stage, the assessment of interest development in folk active plays was originally carried out;

Within the frames of the research there was carried out the questionnaire survey of parents; it gave the opportunity to analyze how important a folk play is in family upbringing

In the third stage, have elaborated and approved a program that includes folk active plays and folk plays-riddles, national games aimed to develop fine motor skills.

\subsection{Running and Description of the Experiment}

Play activity intensifies the development of mental processes randomness: voluntary attention and memory; it promotes the development of mental activity, imagination - transition to thinking in categories of images, sign function of the speech, reflexive thinking, improvement of locomotor and volition activity.

When it comes to the choice of play therapy forms, it is necessary to proceed from specific objectives of mental development correction which may be solved by these means, and from the fact how stable the indicators of play therapy effective impact on the child are.

At present great attention of teachers is paid to a folk play in the work with children with disabilities. It, as well as any other game, performs various upbringing functions (developing, cognitive, entertaining, diagnostic, correcting, etc.) and may serve as a means to introduce children and teenagers to national culture that, in turn, represents the most important aspect of moral-esthetic, universal values system formation (Anikeev, 2011; Volkov, 2006.).

In this context it is possible to agree with S. A. Shmakov's point of view who claims that a play is national and at the same time, it is international, cross-national, all-human (Avdulov, 2009)

The sociocultural sense of a folk play is that it forms standard skills of social behavior being a control criterion of personality traits manifestation. No wonder that experts of different directions have chosen a folk play as an object of research.

The ideas of scientific studying of folk plays and their practical application in upbringing were grounded in the works of V. G. Belinsky. N. A. Dobrolyubov, N. G. Chernyshevsky and others. K. D. Ushinsky considered folk plays as the objective of future pedagogics, as “... excellent and powerful educational means" (Ushinsky, 2000).

National culture is the subject which the person should conceive throughout the life-from their first steps. The earlier we start introducing children to the world of national culture, the better results we achieve. Children's acquaintance with sources of national culture allows to develop patriotic feelings and spirituality of preschool children. Various topics and forms of fascinating lessons acquainting children with the world of national culture, 
may become the foundation for its profound knowledge, may help overcome stereotypes in perception of representatives of other nations, and will serve for the purpose to prevent interethnic conflicts in the youth environment.

The prospects of the existing vocational education system reforming in the Russian Federation are connected with the active introduction of national pedagogics experience into the practice of correctional-pedagogical work integrated with the achievements of pedagogical thought. A folk play has to perform an essential role in the optimization of approaches to training and upbringing of children with special needs.

The analysis of the survey showed that in most cases primary school children love and want to play active folk plays. $70 \%$ of children are interested in active folk plays due to their dynamism and opportunity to show physical activity, especially in running exercises. But children do not have sufficient variety of a game stock.

Within the frames of the research there was carried out the questionnaire survey of parents; it gave the opportunity to analyze how important a folk play is in family upbringing.

The results of questioning allowed to come to the conclusions that parents can recollect no more than two national holidays; moreover they usually do not take part in them. The national holiday which is celebrated in a family with children is "Maslenitsa" or "Sabantuy", but generally the celebration is limited to the feast. In the course of the research it was found out that parents correctly name no more than four outdoor folk plays, but they do not learn them with their children because they forgot the conditions of playing.

The questionnaire of elementary school teachers showed that $60 \%$ of teachers use folk plays in their work with children. But they do not focus attention on advanced studying of folk active plays, and use those that they consider pleasant for them in work with children. Teachers do not focus children's attention on the correct name of this or that play, its features and rules, and often do not have this information.

We have developed the plan of work with primary school children, their parents and teachers aimed to apply folk active plays to preserve national traditions, to establish links between old and modern cultures, to promote the development of spatial orientation.

\section{Results}

Psychological analysis of the lesson showed that children were emotionally free and deeply involved in the activity.

Active plays were held after classes, at physical education lessons, and during breaks.

In the course of playing we paid attention to children's movements and actions, to the way they follow the rules, and their loading.

There were arranged discussions with children: "The Russian national games", "Russian nesting dolls. Dolls from grandmother's chest", "What games did our parents play" to give an idea of folk customs, ceremonies, traditions and holidays, of national folklore and history of national plays, and to keep up interest in them.

Parents participated in two lessons "Maslenitsa" and "Sabantuy"; they played with their children and shared their personal experience with them.

Special attention is paid to the peculiarities of folk riddles that played a significant role in competitions of the past. Riddles are classified according to the degree of difficulty into usual riddles, competitive and adjoining paradox. The problem character is shown: the richness of answers when riddles are guessed, the lack of unambiguous link between the riddle text, on the one hand, and the thought object, on the other hand.

The application of folk developing plays was one more stage. The inclusion of folk developing plays in teaching-educational process of educational institutions may be based on the theory of didactic game developed in pre-school pedagogy. They are united by the definition of dominating program tasks, peculiarities intrinsic to this age group and children's possibilities, preparation of didactic materials. At the same time folk plays significantly differ from didactic ones. They are most often based on sagacity, without connection to a specific training task or sections of the program, not connected with a certain age of children, are interesting for any inquisitive person. They are characterized by competitiveness and entertaining elements that involve children into independent play without adults. Folk plays are always original, they have a fascinating plot, realistic or imaginary characters, they may be considered as an intellectual exercise.

\section{Discussions}

El'konin (2000) underlined that in such games the child "freely communicates with values and meanings - and expands the field of vision including the intellectual one, expands the field of consciousness, strengthens 
self-confidence, belief in the opportunities and forces, forms creative abilities-among them abilities, and sometimes talent for communication, form ethical and moral foundation of practical behavior: forms himself".

Using such developing folk plays as "Geese-Swans", "Golden Gate", "Watchman", etc., we came to the conclusion that folk plays promote the solution of correctional tasks and create conditions necessary for the stimulation of speech activity.

One of the pedagogical conditions singled out by us is the rational organization of the Russian folk play. It is known that any activity is formed gradually.

In our research we have developed some methods of correctional folk play introduction, defined the sequence of work: careful selection of folk plays, game material according to the aims and tasks of logopedic material taking into account specific, mental, speech features of children; preparation of visual-didactic material; organization of children; the main stage providing the choice of methods and techniques aimed to train children in a correctional play in the course of which components of speech and nonverbal functions are formed and corrected

\section{Conclusion}

In the course of our research we have also come to the conclusion that works of folklore, especially magic fairy tales, legends, parables, living traditions of people, national and universal culture of communication, confessional moral values, and other things of people's wisdom produce a favourable effect on children. "In the correctional-developing training the specific weight of knowledge obtained from the surrounding reality increases; the great value is attached to the knowledge gained on the basis of practical experience. These knowledge is introduced in a training process enriching its contents", prominent scientists of correctional pedagogics Andrushchenko T. Yu., Karabekova, N. V. write. The implementation of this important social-pedagogical requirement in the correctional-developing work is determined by the specifics of pedagogical potential of ethnoculture. Ethnoculture has accumulated the major spiritual and moral values, social experience of many generations without assimilation of which the growing personality is not able to reveal their abilities.

Researches of the leading scientists testify that upon pedagogically expedient guide of the teacher-speech pathologist the play promotes the formation of skills of interpersonal communication with peers and positive adaptation in the society of children with disabilities.

\section{Acknowledgments}

The work is performed according to the Russian Government Program of Competitive Growth of Kazan Federal University

\section{References}

Akatov, L. I. (2003). Social rehabilitation of children with disabilities (p. 368). Moscow.

Andrushchenko T. Y., \& Karabekova, N. V. (2012). Correctional and developing plays for children of 6-10 years. Moscow.

Anikeev, N. P. (2011). Up-bringing by play (p. 150). M.: Prosveshchenie (Education).

Avdulova, T. P. (2009). Psychology of play modern approach: Study guide for students of higher education institutions (p. 208). M.: Publishing center "Akademiya".

El'konin, D. B. (2000). Psychology of play. Moscow.

Grigorieva, L. G. (2002). Children with problems in development (p. 213). Moscow, Akademkniga.

Sokolova, N. D. (2005). Children with disabilities: Problems and innovative tendencies in training and education (p. 180). Moscow.

Stepanova, O. A., Weiner, M. E., \& Chutko N. Ya. (2007). A game technique with correctional—Developing technologies. Moscow.

Ushinsky, K. D. (2000). Upbringing of a person (p. 255). Moscow.

Volkov, G. N. (2006). Ethnopedagogics. Cheboksary.

Vygotsky, L. S. (2006). Game and its role in the child's psychological development. Questions of Psychology, 5. 


\section{Copyrights}

Copyright for this article is retained by the author(s), with first publication rights granted to the journal. This is an open-access article distributed under the terms and conditions of the Creative Commons Attribution license (http://creativecommons.org/licenses/by/3.0/). 